
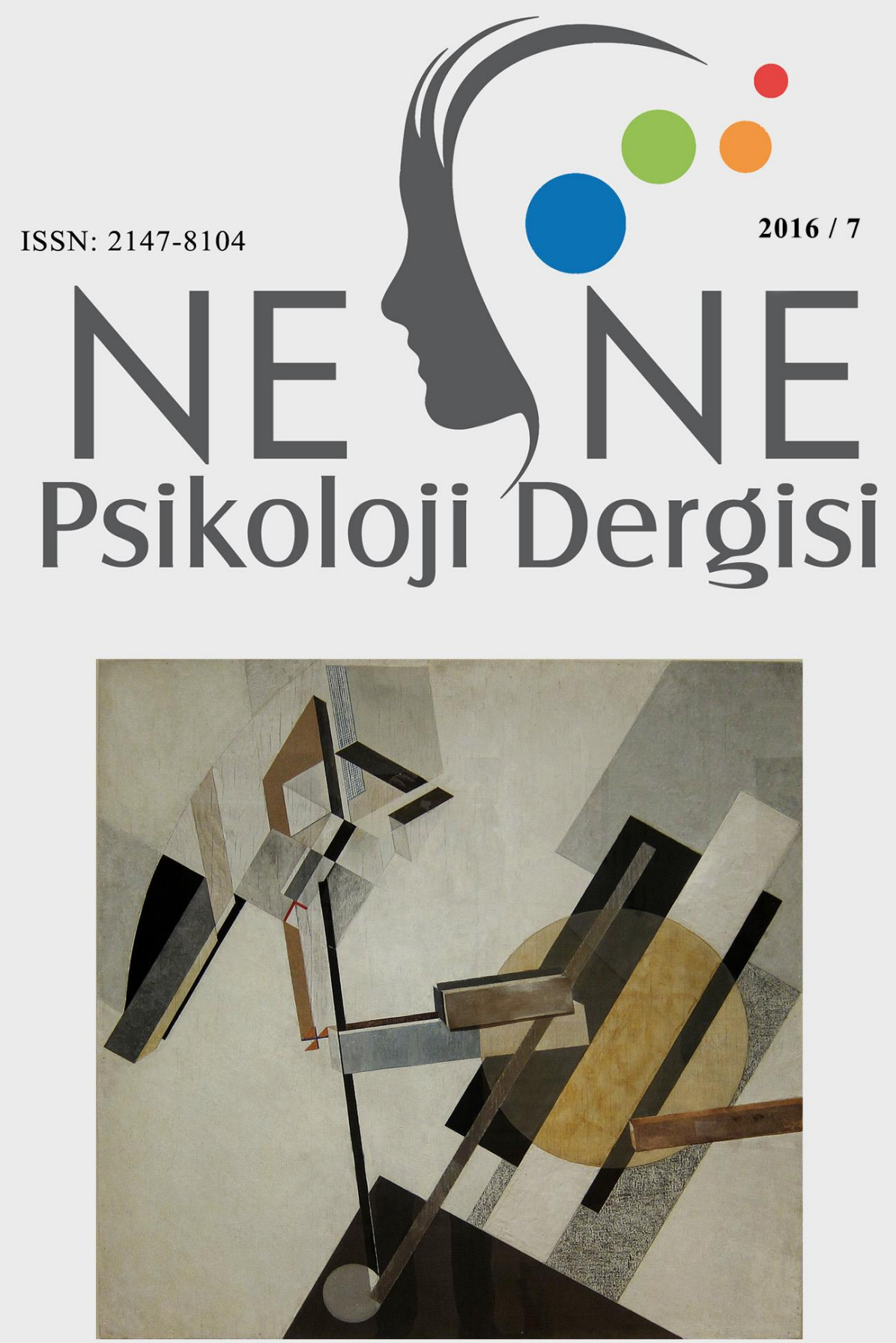

El Lissitzky (1890-1941)

www.nesnedergisi.com 


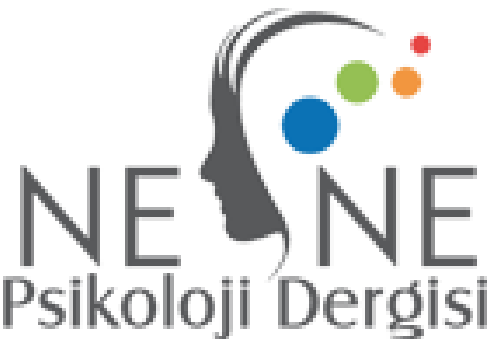

Nesne Dergisi'ne gönderilecek yazıların özgün olması ve evrensel bilime katkıda bulunması beklenmektedir. Bununla birlikte, bilim insanlarını tanıtan, yeni etkinlikleri veya yayımları duyuran yazılara ve röportajlara da yer verilir.

Makalelerin Nesne'de yayımlanabilmesi için, daha önce bir başka yerde yayımlanmamış ve yayımlanmak üzere kabul edilmemiş olması gerekir. Daha önce sempozyum, kongre v.b bilimsel toplantılarda sunulmuş; ancak yayımlanmamış bildiriler ile lisans ve lisansüstü tezlerden üretilmiş çalışmalar da yayıma kabul edilir.

Nesne, Yaz/Haziran ve Kış/Aralık olmak üzere yılda iki sayı olarak yayımlanır. Dergi, Yayım Kurulu tarafından belirlenen yurt içi ve dışındaki kütüphanelere, uluslararası indeks kurumlarına ve abonelere yayımlandığ tarihten itibaren bir ay içerisinde gönderilir.

Nesne'de yayımlanması kabul edilen yazıların telif hakkı Nesne Psikoloji Dergisi'ne devredilmiş sayılır. Yayımlanan yazılardaki görüşlerin sorumluluğu yazarlarına aittir. Dergideki yazı ve fotoğraflardan kaynak gösterilerek alıntı yapılabilir.

Nesne'nin yayım dili Türkçe ve İngilizce'dir.

\section{About NESNE}

Articles to be sent to Nesne Psychology Journal are expected to be original and to contribute to universal science. Moreover, the journal gives place to articles and interviews that introduce scientists, artists and publications.

In order for an article to be published in Nesne, it is necessary for it not to be published anywhere before or accepted to be published. Papers that have been presented in a symposium or conference before but have not been published and studies produced from undergraduate thesis, master's thesis and dissertation are also welcomed.

Nesne is published two times a year: Summer/June and Winter/December. At the end of each year, the index of the journal is prepared and punlished in Winter issue. The journal is sent to the libraries in the country and abroad, international index institutions and subscribes by the editorial board within a month after publication.

Nesne; Asos Index, CEEOL, DOAJ, ERIH PLUS, Index Copernicus, Ulrich's Periodicals Directory (ProQuest) ve Türk Psikiyatri Dizini tarafından listelenmektedir. 
ISSN: 2147- 6489 Sayı/Number:7 $\quad$ Yaz/Summer 2016

\section{ARTSÜREM}

İmtiyaz Sahibi / Publisher

Sanat ve Dil Araştırmaları Enstitüsü

\section{Genel Yayın Yönetmeni / Editor in Chief}

Sezin BAŞBUĞ

Elektronik Yayın Yönetimi ve Tasarım / Web Management and Design

Eşref YARIMCA

Düzelti / Revision

Ahmet Çağlar OK, Dürdane GÜMÜŞTEN,

Nur BİRINCI

Röportaj Editörü

Fatma YAŞIN

$\underline{\text { Kapak Resimleri / Cover }}$

El Lissitzky (1890-1941)

Yazı işleri Müdürü / Managing Editor

Fırat BAŞBUĞ

$\underline{\text { Yazıșma Adresi / Correspondence Address }}$

Kuleli Sokak, 49/24, Gaziosmanpaşa, Çankaya/ANKARA

Telefon: 03124460278

Yayımlanma Tarihi: 21.06.2016

www.nesnedergisi.com

bilgi@nesnedergisi.com 


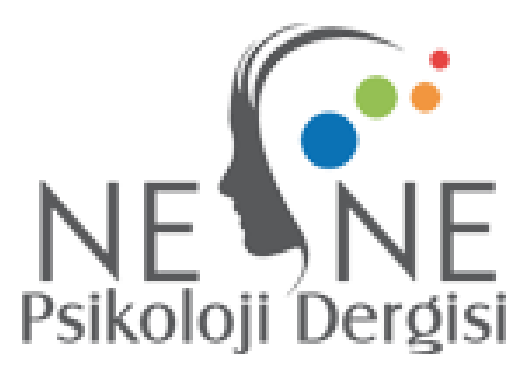

\section{YAYIN KURULU / EDITORIAL BOARD}

Doç. Dr. Banu YILMAZ (Ankara Üniversitesi)

Doç. Dr. Belma BEKÇİ (Okan Üniversitesi)

Doç. Dr. Derya HASTA (Ankara Üniversitesi)

Doç. Dr. Mediha KORKMAZ (Ege Üniversitesi)

Doç. Dr. Michelle ADAMS (Bilkent Üniversitesi)

Yrd. Doç. Dr. Zuhal YENIÇERİ (Başkent Üniversitesi)

Dr. Ebru AKÜN (Ankara Üniversitesi)

Öğr. Gör. Gizem CESUR (İstanbul Ticaret Üniversitesi)

Arş. Gör. Cihat ÇELIKK (Ankara Üniversitesi)

Arş. Gör. Fatma YAŞIN (Ankara Üniversitesi)

Arş. Gör. İbrahim YİĞİT (Ankara Üniversitesi)

Arş. Gör. Matthew D. MARRERO (University of New Orleans)

Arş. Gör. Melike GUZEY (Ankara Üniversitesi)

Arş. Gör. Melis ÇELIKK OK (Ankara Üniversitesi)

Arş. Gör. Özge AKBALIK (Ankara Üniversitesi)

Arş. Gör. Selin KÖKSAL ARAÇ (Çukurova Üniversitesi) 


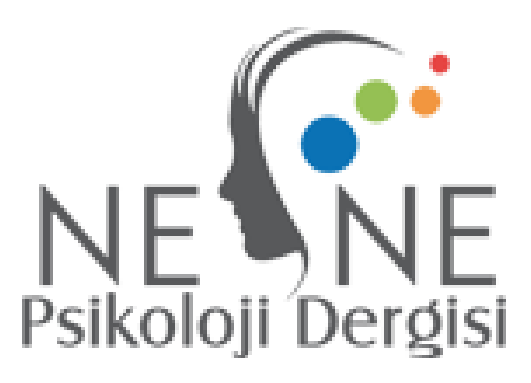

HAKEM VE DANIŞMA KURULU / REFEREE AND ADVISORY BOARD

Prof. Dr. Ali DÖNMEZ (Çankaya Üniversitesi)

Prof. Dr. Aylin KÜNTAY (Koç Üniversitesi)

Prof. Dr. Ayşegül DURAK BATIGÜN (Ankara Üniversitesi)

Prof. Dr. Ayşen GÜRE (Ankara Üniversitesi)

Prof. Dr. Doğan KÖKDEMİR (Başkent Üniversitesi)

Prof. Dr. Hamit COŞKUN (Abant İzzet Baysal Üniversitesi)

Prof. Dr. Gülsen ERDEN (Ankara Üniversitesi)

Prof. Dr. Melike SAYIL (Hacettepe Üniversitesi)

Prof. Dr. Nilhan SEZGIN (Ankara Üniversitesi)

Prof. Dr. Nurhan ER (Ankara Üniversitesi)

Prof. Dr. Robert LAIRD (University Of New Orleans)

Prof. Dr. Selim HOVARDAOĞLU (Ankara Üniversitesi)

Prof. Dr. Sezen ZEYTINOĞLU (İzmir Üniversitesi)

Prof. Dr. Şennur KIŞLAK (Ankara Üniversitesi)

Prof. Dr. Tevfika TUNABOYLU İKIZ (İstanbul Üniversitesi)

Prof. Dr. Zehra YAȘIN DÖKMEN (Ankara Üniversitesi)

Doç. Dr. Ayda BÜYÜKŞAHIN SUNAL (Ankara Üniversitesi)

Doç. Dr. Engin ARIK (Doğuş Üniversitesi)

Doç. Dr. Ersin KUŞDİL (Uludağ Üniversitesi)

Doç. Dr. Gülay DİRIKK (Dokuz Eylül Üniversitesi)

Doç. Dr. Işı1 BİLİCAN (İstanbul Medeniyet Üniversitesi)

Doç. Dr. Okan Cem ÇIRAKOĞLU (Başkent Üniversitesi) 
Doç. Dr. Orçun YORULMAZ (Uludağ Üniversitesi)

Yrd. Doç. Dr. Aydın KARAÇANTA (İstanbul Ticaret Üniversitesi)

Yrd. Doç. Dr. Duygu GÜNGÖR CULHA (İzmir Üniversitesi)

Yrd. Doç. Dr. Ekrem DÜZEN (İzmir Üniversitesi)

Yrd. Doç. Dr. Elif ÇELEBİ (İstanbul Şehir Üniversitesi)

Yrd. Doç. Dr. Göklem TEKDEMIR YURTDAŞ (İstanbul Üniversitesi)

Yrd. Doç. Dr. Hüdayar Cihan GÜNGÖR (Y1ldırım Beyazit Üniversitesi)

Yrd. Doç. Dr. Hüseyin BOYACI (Bilkent Üniversitesi)

Yrd. Doç. Dr. Oğuz YURTTADUR (Selçuk Üniversitesi)

Yrd. Doç. Dr. Saniye BENCIK KANGAL (Hacettepe Üniversitesi)

Yrd. Doç. Dr. Sema BENGİ GÜRKAN (Toros Üniversitesi)

Yrd. Doç. Dr. Sema KARAKELLE (İstanbul Üniversitesi)

Yrd. Doç. Dr. Timuçin AKTAN (Çağ Üniversitesi)

Öğr. Gör. Dr. Mine CiHANOĞLU (Atılım Üniversitesi)

Dr. Semra AZIZZOĞLU (Ankara Üniversitesi)

Dr. Semra ŞAHIN (Hacettepe Üniversitesi)

Öğr. Gör. Banu ELMASTAŞ DİKEÇ (Uludağ Üniversitesi)

Öğr. Gör. Fatma BOYRAZ (Ankara Üniversitesi)

Psk. Levent Bekir TELLİ (Çukurova Üniversitesi) 


\section{NESNE PSÍKOLOJİ DERGISİ}

\section{Amaç ve Kapsam}

Nesne Psikoloji Dergisi'nde (NPD) görgül araştırma ve derleme türü yayınlara (en son literatürü kapsamlı bir şekilde kapsayan yazılar ve olgu sunuları); ayrıca lisans, yüksek lisans ve doktora tez makalelerine de yer verilmektedir. Tüm yazılar Amerikan Psikologlar Birliği tarafindan yayınlanan 'Publication Manual of American Psychological Association (5. Bask1), 2001' adlı kitapta belirtilen yazım ilkelerine uygun olarak yazılmalıdır.

Psikolojinin klinik, gelişim, sosyal, endüstri ve örgüt psikolojisi, deneysel psikoloji ve psikometri olmak üzere bütün alanlarından özgün çalışmaların yayıma kabul edildiği Nesne'de, lisans, yüksek lisans ve doktora tezlerinden üretilen yayınlara öncelikli olarak yer verilecektir. Ayrıca dergide, bilim insanlarından gelen kuramsal, uygulamalı ve ayrica disiplinler arası çalışmalar da yayımlanacaktır. Bununla birlikte, bilim insanlarını tanıtan, yeni etkinlikleri veya yayınları duyuran yazılara ve röportajlara da yer verilecektir. Derginin temel amacı, genç bilim insanlarının psikoloji bilimine olan katkılarını arttırmaktır.

\section{Yazıların Değerlendirilmesi}

Nesne Psikoloji Dergisi'ne gönderilen yazılar, önce editörce dergi ilkelerine ve yazım kurallarına uygunluk açısından incelenir. Uygun görülen yazılar, Yayım Kurulu'na iletilir. Editör ve/veya Yayım Kurulu, gelen yazının içeriğini inceler, makalenin hakem değerlendirmesine alınıp alınmayacağına karar verir. Hakem değerlendirmesine alınması uygun görülen makaleler ilgili alanda iki hakeme gönderilir. Editör ve/veya Yayım Kurulu, gelen hakem raporlarına göre yazının yayımlanıp, yayımlanmayacağına karar verir. Yayım Kurulu tarafindan, yayımlanmasına karar verilen yazılar, editörce yayım sırasına alınır ve yazarlara bilgi verilir.

Nesne Psikoloji Dergisi'nde yayımlanması kabul edilen yazıların telif hakkı Nesne Psikoloji Dergisi'ne devredilmiş sayılır. Yayımlanan yazılardaki görüşlerin sorumluluğu yazarlarına aittir. 


\section{NESNE PSİKOLOJİ DERGISİ YAZIM VE YAYIM İLKELERİ}

\section{Yayım Dili}

Nesne Psikoloji Dergisi'nin yayın dili Türkçe ve İngilizce'dir.

\section{Genel İlkeler}

1. Dergiye gönderilecek yazılar, A4 boyutlarında beyaz kağıda üst, alt, sağ ve sol boşluk 2,5 cm. Birakılarak (16 x 24,7'lik alana)Microsoft Word programında Times New Roman yazı tipinde 12 punto ve 1,5 satır aralığıyla, düz metin olarak yazılmalıdır.

2. Yazılarda Türk Dil Kurumu'nun yazım kılavuzu dikkate alınmalı, yabancı sözcükler yerine olabildiğince Türkçe sözcükler kullanılmalıdır. Türkçe' de yaygın olarak kullanılmayan sözcükler yazıda kullanılırken ilk geçtiği yerde yabanc1 dildeki karşılığı parantez içinde verilmelidir (Türkçe ve İngilizce).

3. Yazılar başlık, öz (Türkçe ve İngilizce), anahtar kelimeler, ana metin, kaynaklar, ekler, tablolar, şekil başlıkları, şekiller ve yazar notları bölümlerini içermelidir.

a) Başlık: En fazla 10-12 kelimeden oluşan makale başlığı (kelimeler arasındaki boşluklar ile beraber en fazla 50 karakter) bu sayfada yer almalıdır.

Yazar adı: Başlığın altına yazılmalı, görev ünvanı, kurum adresi ve e-posta bilgileri bir yıldızla soyadına ilintilendirilerek, ilk sayfanın altında verilmelidir.

b) Öz ve anahtar kelimeler: Öz, Türkçe ve İngilizce olmak üzere her iki dilde 'Öz' ve 'Abstract' başlıkları altında 200 kelimeyi geçmeyecek şekilde olmalıdır. Anahtar kelimeler (3 ile 5 arasında) Türkçe özetin altında 'Anahtar kelimeler' ve İngilizce özetin altında 'Keywords' başlığı kullanılarak verilmelidir. Türkçe ve İngilizce özetin her biri yeni bir sayfadan başlamalıdır.

c) Ana metin: Yeni bir sayfadan başlamalıdır. Görgül makalelerde metin, sırasıyla giriş, yöntem, bulgular ve tartışma bölümlerinden oluşmalıdır. Derleme türü makalelerde, makalenin içeriğine bağlı olarak bu sıra değişebilir. Kısa başlık her sayfanın sağ köşesinde, yanında sayfa numarası olacak şekilde tekrarlanmalıdır. Makalenin başlığı ana metnin ilk sayfasında yer almalı ve başlıktan sonra, "Giriş" alt başlığı yazılmadan paragraf ile metne başlanmalıdır. Yöntem, Bulgular ve Tartışma bölümleri yeni bir sayfadan başlamamalıdır; bir bölüm bittikten sonra, diğeri onu aynı sayfada izlemelidir.

Giriş bölümü, yapılan araştırma ile ilgili olarak, alanyazındaki yaklaşım ve bulgular ile araştırmanın amacını içermelidir. Yöntem bölümü örneklem, veri toplama araçları ve işlem olmak üzere 3 alt bölümden oluşmalıdır. Bulgular araştırmanın denencelerini test etmek amacı ile kullanılan istatistiksel analizleri, her değişkene ait ortalama ve standart sapma değerlerini içermelidir. Tablolar ve şekiller ayrı bir sayfada yazının en sonunda verilmelidir. Verilecek olan tablolarda ortalamalar "Ort." şeklinde, standart sapmalar ise "S" şeklinde gösterilmelidir.

Tartışma bölümü, araştırma bulgularının alanyazın ışığında açıklanmasını, tartışılmasını içermelidir.

d) Kaynaklar: Yeni bir sayfadan başlamalıdır. Metin içinde belirtilen tüm kaynaklar 'Kaynaklar' listesi içinde yer almalıdır.

Metin içinde kaynaklara atıfta bulunurken yazarların soyadları ve yayın tarihi kullanılır.

Örnekler: 
Köksal (2011) ...

Köksal' a (2011) göre ...

Dils ve Boroditsky (2010) ...

Dills ve Boroditsky'a (2010) göre ...

Yazar sayısı 3 ile 5 arasında ise, metin içinde ilk geçtiği yerde yukarıda olduğu gibi verilir; yazar sayısı 6 veya daha fazla ise metin içinde ilk geçtiği yerden itibaren 'Stallard ve arkadaşları (2010)' olarak verilmelidir. Cümle sonunda birden fazla esere atıfta bulunuluyor ise kaynaklar parantez içinde alfabetik sıra ile verilmelidir

... (Baggerly ve Exum, 2008; Gil,1991; Landreth, 2002).

Kaynaklar bölümünde kaynaklar alfabetik sıra ile verilmelidir.

e) Ekler: Yeni bir sayfadan başlamalıdır. Araştırmada kullanılan ölçekler bu bölümde yer almalidir.

f) Tablolar: Yeni bir sayfadan başlamalı ve her bir tablo ayrı bir sayfada verilmedir. Tablo numarası ve Tablo başlığı tablonun üstünde kelimelerin baş harfleri büyük olarak yer almalıdır. Gönderilecek olan tablolar mutlaka Word programının "Tablo" seçeneği kullanılarak ve APA'ya uygun olarak hazırlanmalıdır.

g) Şekil başlıkları ve şekiller: Yeni bir sayfadan başlamalıdır. Şekil numarası ve şekil başlıkları kelimelerin baş harfleri büyük olarak aynı sayfada alt alta verilmelidir. Şekillerin her biri ise ayrı sayfalarda verilmelidir. Gönderilecek olan tablolar ve şekillerin toplam sayısının 5 ya da 6'yı geçmemesine özen gösterilmelidir.

h) Yazar notları: Yeni bir sayfadan başlamalıdır. Eğer araştırma bir tez çalışmasının özeti ise veya araştırmayı destekleyen kurum(lar) var ise bu bölümde belirtilmelidir. Ayrıca araştırmacının, araştırmaya katkılarından dolayı teşekkür etmek istediği kişiler de bu sayfada belirtilmelidir.

4. Yazılarda ifade edilen düşüncelerden yazarları sorumludur.

5. NPD'de yayınlarından ancak kaynak gösterilerek alıntı yapılabilir. Yazının içeriğinde olabilecek çarpıtmalardan alıntıyı yapan ve yayımlayan kişi ya da kuruluşlar sorumludur.

6. Yayım Kurulu, yazıda gerekli gördüğü sözcükleri değiştirebilir.

7. Kurallara uymayan yazılar yayımlanmaz.

8. Yayımlanan her araştırmanın verilerinin 5 yıl süre ile araştırmacı tarafından saklanması zorunludur. Gerek yayın politikamız gerekse uluslararası yayım kuruluşlarının kuralları gereğince zaman zaman bazı yazıların verileri ve analiz programları yazarlarından istenebilecektir. 


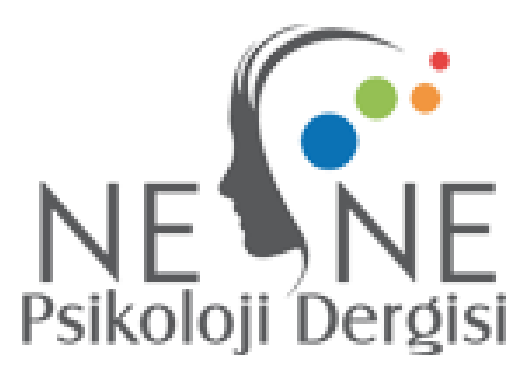

$\underline{\text { ISSN: 2147- } 6489 \text { Sayı/Number:7 }}$ Yaz/Summer 2016

\author{
İÇINDEKILER / CONTENTS
}

ROMANTIK İLIŞKIILERDE ÇATIŞMA ÇÖZÜM STİLLERİ ÖLÇEĞİ:

GEÇERLİK GÜVENIRLIKK ÇALIŞMASI

Ayça ÖZEN, Selin SALMAN ENGİN, Nuray SAKALLI UĞURLU 1

İŞYERINNDEKİ PROBLEMLERE VERILLEN TEPKILER ÖLÇEĞİ: GEÇERLIKK VE GÜVENIRLIK ÇALIŞMASI

Seçil KESKİN .21

OBSESIFF KOMPULSİF BOZUKLUKTA BAĞLANMA, OBSESİF İNANÇLAR VE DUYGU DÜZENLEME ZORLUKLARI: KLINIKK VE KLINIIK OLMAYAN ÖRNEKLEM KARŞILAŞTIRMASI

Sevgi VATAN 41

KOLEKTİF SUÇLULUK: ÖNCÜLLERİ, ÇIKTILARI VE KAÇINMA YOLLARI

Nuray SAKALLI UĞURLU, Bilge SOYLU .59

THE PREDICTIVE POWER OF RELIGIOUS ORIENTATION TYPES ON AMBIVALENT SEXISM

Fatih ÖZDEMIR 89

TÜBERKÜLOZ HASTALARINDA STRES VE STRESLE İLIŞKİLİ FAKTÖRLER

Gül ULUBAYRAM, Ayşegül DURAK BATIGÜN . 109

PROF. DR. PHILIP ZIMBARDO İLE KÖTÜLÜK PSİKOLOJISİ ÜZERİNE...

Fatma YAŞIN, Sezin BAŞBUĞ 131 